ISSN: 0213-2052 - eISSN: 2530-4100

DOI: https://doi.org/10.14201/shha2021392750

\title{
DELFOS EN LAS AVENTURAS COLONIALES ESPARTANAS DEL ARCAÍSMO, I. FALANTO Y LAS TRADICIONES SOBRE LA KTISIS DE TARENTO
}

\section{Delphi in the Spartan Colonial Adventures of the Archaic Period, I. Phalantos and the Traditions on the Taranto's Ktisis}

\author{
César FORNIS \\ Universidad de Sevilla \\ cfornis@us.es \\ ORCID: https://orcid.org/0000-0002-9389-6592 \\ Javier JARA \\ Universidad de Salamanca \\ javijara@usal.es \\ ORCID: https://orcid.org/0000-0001-9486-0930
}

Fecha de recepción: 29-9-2020 Fecha de aceptación: 30-11-2020

RESUMEN: En la época arcaica los espartanos apenas toman parte activa en el fenómeno colonizador griego. Según la tradición dominante, su única fundación, Taras (Tarento), daba solución a los problemas internos causados en la metrópoli por los llamados partenias, hijos ilegítimos nacidos durante la primera guerra mesenia a los que se había privado de la ciudadanía plena y del acceso a la tierra que conlleva. En el presente trabajo analizamos cómo, en el marco de la privilegiada relación simbiótica que mantuvieron Delfos y Esparta, el santuario contribuyó decisivamente 
con oráculos ex eventu tanto a la legitimación de una ktisis debida a un grupo marginal como al proceso de heroización de su oikistes, Falanto.

Palabras clave: Delfos; oráculos; Esparta; Falanto; Taras; Tarento; colonización griega; tradiciones orales; partenias.

ABSTRACT: In the Archaic Period the Spartans hardly took an active part in the Greek colonizing phenomenon. According to the dominant tradition, its only foundation, Taras (Taranto), provided a solution to the internal problems caused in the metropolis by the so-called partheniai, illegitimate children born during the first Messenian war who had been deprived of full citizenship and access to the land that it implies. In this paper we analyze how, within the framework of the privileged symbiotic relationship maintained by Delphi and Sparta, the sanctuary contributed decisively with oracles ex eventu both to the legitimation of a ktisis due to a marginal group and to the process of heroization of the oikistes, Phalantos.

Keywords: Delphi; oracles; Sparta; Phalantos; Taras; Taranto; Greek colonization; oral traditions; partheniai.

En lo que se ha dado en llamar "la tradición constitucional» lacedemonia, los ciudadanos tenían prohibido viajar más allá de las fronteras del Estado sin permiso de las autoridades (Xen. Lac. 14.4; Arist. fr. 543 Rose; Pl. Prt. 342D, que la hace extensiva a los cretenses; Isoc. 11.18; Nic. Dam. FGrH 90F103z 5; Plut. Lyc. 27.6, Agis 11.2 y Mor. 238D). La medida, atribuida como tantas otras instituciones y costumbres a Licurgo, cuasidivino demiurgo creador del kosmos espartano, no tenía otro fundamento que el temor a la corrupción que puede producirse al entrar en contacto con extraños al mismo (Xen. Lac. 14.4; Plut. Lyc. 9.5 y 27.7-9, Mor. 238D-E;

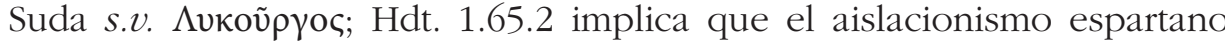
habría sido anterior al mítico nomothetes). Antes de su victoria sobre la arche ateniense a finales del siglo $\mathrm{V}$, los espartanos eran muy reacios a salir del Peloponeso, su "casa", el corazón de su imperio (en Thuc. 1.70.4 los

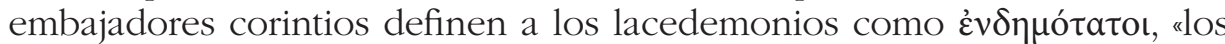

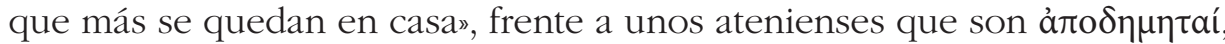
"aficionados a los viajes"). Hubo no obstante dos momentos en los que, debido a especiales circunstancias, los espartanos abandonaron su caparazón y emprendieron aventuras marítimas que se enmarcan en la expansión colonial que caracterizó la época arcaica griega; de la participación del oráculo de Delfos en la primera de ellas, concretada en la fundación de Tarento, nos vamos a ocupar aquí, mientras dejamos para otra ocasión 
la influencia délfica en la segunda, aquella que dos siglos después y encabezada por Dorieo se vio abocada al fracaso.

Como es sabido, normas no escritas prescribían que, antes siquiera de que los colonos embarcasen, los oikistai consultaran la idoneidad de sus iniciativas con un oráculo de Delfos que a lo largo del Arcaísmo se fue forjando como el principal santuario panhelénico merced a su implicación en los vaivenes sociopolíticos de los diferentes Estados griegos ${ }^{1}$. No obstante, cabe matizar que el proceso fue paulatino y que un procedimiento regulado y sistemático de consulta a la pitia es poco verosímil en una época temprana; aún hoy siguen siendo válidas las palabras de George Forrest hace más de seis décadas: «En los comienzos, la colonización fue de lejos más responsable del triunfo de Delfos que Delfos del triunfo de la colonización $»^{2}$.

Por otro lado, Esparta fue el Estado griego más estrechamente vinculado con Delfos, ya desde su mismo nacimiento y configuración como polis; al fin y al cabo, Apolo era el dios más presente, bajo distintas advocaciones - entre las que destaca poderosamente la de Piteo (Paus. 3.10.8

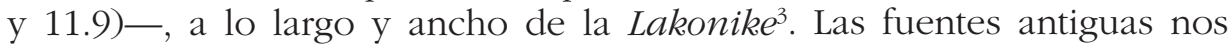
transmiten, en este sentido, cómo el ordenamiento constitucional lacedemonio atribuido al mítico Licurgo fue refrendado y sacralizado por el oráculo para convertirlo en ley inmutable (Tyrt. fr. 3D apud Diod. Sic. 7.12.6; Hdt. 1.65.2; Plut. $L y c$. 6.1-2 y 10) ${ }^{4}$. Incluso el peculiar sistema diárquico de los espartanos, en el que dos reyes ejercían el poder en teórica igualdad de condiciones, habría quedado sancionado por la pitia délfica (Hdt. 6.52; Pl. Leg. 691D-E) ${ }^{5}$. Además, Esparta fue la única polis documentada que contó con personal especializado en las relaciones con Delfos, los pitios ( $\pi \dot{v} \theta$ เo $)$, nombrados por los diarcas y, junto a estos, custodios de los libros con los oráculos y alimentados a expensas del erario público (Hdt. 6.57.2 y 4; Xen. Lac. 15.5); si bien los pitios no tenían la exclusividad en las consultas al santuario, dan fe ciertamente de una relación privilegiada

1. Con carácter general: Forrest, "Colonization»; Malkin, Religion, esp. 17-91; Londey, "Greek Colonists»; Morgan, Athletes, 172-178; Moscati Castelnuovo, «Ecisti».

2. Forrest, "Colonization", 174. Como posición extrema, Defradas, Thèmes, 233-257, afirma que «el mito de Apolo délfico arquegeta es posterior al gran período de la colonización» (p. 237), una invención tardía (a partir del siglo VI) del clero délfico, y en la misma línea se sitúa Fontenrose, Delphic Oracle, passim.

3. Véase Fornis, Esparta, 410-420, que recoge la literatura científica anterior.

4. Sobre la figura omnipresente de Licurgo como demiurgo creador del kosmos espartano, véase en último lugar Nafissi, "Lykourgos». El mito licurgueo impregna toda la tradición occidental: Fornis, Mito, passim.

5. Para la diarquía espartana, el mejor estudio sigue siendo Carlier, Royauté, 240-324. Las principales hipótesis sobre su origen en Fornis, Esparta, 64. 
y fluida entre Delfos y los dinastas agíadas y euripóntidas ${ }^{6}$. De hecho, esta posesión, control e interpretación de los oráculos, como sucede con todo lo que se refiere al orden divino, coadyuvó de manera eficaz al sostenimiento y perpetuación de una politeia espartana de marcado perfil autoritario ${ }^{7}$. Los lacedemonios, de los que Heródoto dice que "consideraban las cosas de los dioses más elevadas que las de los hombres» (5.63.2), se sentían por tanto especialmente ligados a los designios del santuario délfico y acataban con particular diligencia y solemnidad las respuestas de la pitia, muchas de las cuales, debidamente instrumentalizadas, habrían de tener una decisiva influencia en el devenir histórico de su polis.

Sin embargo, la implicación de Esparta en el movimiento de expansión colonial griega del Arcaísmo parece más bien escasa, dado que la conquista de una parte significativa del fértil territorio de los mesenios tras la primera guerra contra ellos había paliado parcialmente la temible stenochoria o escasez de tierras productivas en Laconia, sin duda la primera causa de migración entre los griegos, aunque como veremos no había puesto fin a los conflictos internos por el acceso a la ciudadanía y a la tierra $^{8}$. De hecho, la única apoikia espartana confirmada por la arqueología es Taras, actual Tarento, en el golfo al que da nombre - el conocido como Mar Piccolo - en el extremo meridional de la península itálica?

La principal fuente literaria sobre la leyenda fundacional tarentina es Estrabón (6.3.2-3), que aúna en su relato la tradición de Antíoco de Siracusa (FGrH 555 F13), de la segunda mitad del siglo V, y la de Éforo de Cime ( FGrH 70 F216), de mediados del IV ${ }^{10}$. Ambas coinciden en enmarcar la ktisis en el contexto de la primera guerra mesenia, el conflicto que consolidó el dominio lacedemonio en la península peloponésica en la segunda mitad del siglo VIII (Tyrt. fr. 4D; Paus. 4.5.10); la conexión es reafirmada por Eusebio de Cesarea, quien aportaba el año 706 como fecha fundacional (Chron, p. 91 1l. 25-26 Helm), que el registro arqueológico ha

6. Parke y Wormell, Delphic Oracle, I, 84, 417; Fontenrose, Delphic Oracle, 164; Carlier, Royauté, 267-269, que piensa que desde el siglo V los pitios irían perdiendo progresivamente importancia; Richer, Religion, 264 n. 113, 284-285.

7. Morgan, Athletes, 171.

8. Morgan, Athletes, 170; Nafissi, Nascita, 38-39. Bérard, Colonisation, 169, y Cartledge, Sparta, 124, matizan que, con todo, no se puede aislar a Esparta de la oleada colonizadora agraria de los griegos.

9. Mucho más tarde, en plena guerra del Peloponeso y por motivos bien distintos, los espartanos fundaron Heraclea de Tráquide, que pese a gozar del apoyo délfico fue hostigada sin cesar por los pueblos vecinos (Thuc. 3.92-93; Diod. Sic. 12.59.3-5; cf. Moscati Castelnuovo, «Ecisti», 18-20 sobre la consulta oracular).

10. Los textos originales y la traducción italiana de todas las fuentes literarias y epigráficas sobre los orígenes de Taras en Lippolis, Garraffo y Nafissi, Culti, 263-289. 
venido a confirmar ${ }^{11}$. Tampoco presenta dudas la impronta laconia en la cultura y las instituciones tarentinas ${ }^{12}$, por más que luego siguieran senderos diferentes. Pero más allá de estos datos, el historiador moderno corre el riesgo de perderse entre relatos de fundación que son el resultado de distintos intentos realizados a lo largo del tiempo por ordenar la realidad, a través de los cuales «la ciudad se pone, o es puesta, bajo precisas coordenadas de orden político, social y moral ${ }^{13}$.

Una de las versiones ofrecidas por el geógrafo de Amasia (6.3.2), la correspondiente al Peri Italias del siracusano, incluye al oráculo de Delfos como uno de los actores principales. Comenzada la guerra contra los mesenios, aquellos espartiatas que rehusaron participar en la contienda fueron reducidos al hilotismo ${ }^{14} \mathrm{y}$ los hijos nacidos de sus uniones con las doncellas (parthenoi) mientras los homoioi combatían en Mesenia,

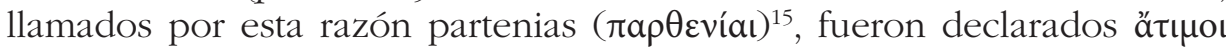

11. Lo Porto, «Satyrion"; Stibbe, "Sparta»; Boschung, "Archaischen»; Neeft, "Tarantine». No obstante, esta datación bien afianzada en la historiografía moderna ha sido puesta en duda por Meier, Aristokraten, 138-140, para quien, en primer lugar, la aparición de cerámica de origen corintio y argivo junto a la de estilo laconio mostraría que su presencia sería fruto del comercio de importación y no el resultado de un asentamiento griego; por otra parte, también han sido descubiertos restos de cerámica laconia en las localidades actuales de Scoglio del Tonno y Porto Cesáreo, que no fueron tomadas por los partenias, lo cual representa para Meier un elemento más para mantener el escepticismo; además, para el historiador alemán, en el siglo VIII Esparta constituía una sociedad pequeña que no podría permitirse el lujo de deshacerse de un considerable número de individuos, independientemente de su origen social. La fecha propuesta por Meier para el asentamiento de Taras es en torno a 630. Parker, "Dates", 29-31 et passim disocia la fundación de Taras, cuya datación a finales del siglo VIII acepta, de la primera guerra mesenia, que con distintos argumentos retrasa a la primera mitad del VII.

12. Véase sobre todo Nafissi, «Sparta».

13. Lippolis, Garraffo y Nafissi, Culti, 156.

14. Reducir al hilotismo a tan numeroso grupo constituiría algo inaceptable para la Esparta del siglo VIII (cf. Meier, Aristokraten, 126-131). En una Esparta que en el orden interno conoció un abigarrado conjunto de categorías y subcategorías sociales, la deshonra

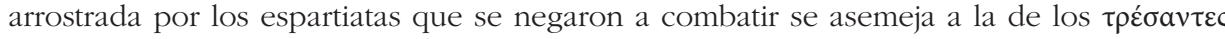
o "Cobardes» (Nafissi, Nascita, 40; Moscati Castelnuovo, «Iloti», 72-75, para la cual partenias evocaría el comportamiento propio de una doncella y no de un varón), convertidos en atimoi desclasados y rechazados por la comunidad, pero no en esclavos.

15. Una comparativa jerarquizada de las fuentes antiguas sobre los partenias, subrayando sus discrepancias e incoherencias, es realizada por Sakellariou, Memory, 67-76, 8690. Pugliese Carratelli, "Storia», 138-139 construyó la alambicada teoría de que los partenias eran población predoria privada de derechos políticos por vía paterna, pero que, al ser sus madres de condición libre, podían participar en las hiera de la ciudad, y específicamente en el culto a Jacinto, como descendientes, según él, de los originales cultores micénicos. No faltan estudiosos (Wuilleumier, Tarente, 39-41; Pembroke, "Femmes", 1265; Philippides, "Partheniai», passim; Malkin, Religion, 216 y Myth, 139; Parker, "Dates», 29) que sospechan 
y privados de la ciudadanía ${ }^{16}$. En la Historia universal de Éforo (Strabo 6.3.3; cf. Arist. Pol. 1306b27-31; Polyb. 12.6b.5; Dion. Hal. 19.1.2-4; Just. Epit. 3.4.3-7; Isid. Etym. 9.2.81), que trata de dignificar el relato de la fundación de Tarento eliminando el elemento hilótico ${ }^{17}$, son en cambio espartiatas demasiado jóvenes como para haber prestado el juramento de no regresar a Esparta hasta haber vencido quienes, a partir del décimo año de la guerra y a fin de evitar la falta de nacimientos de futuros ciudadanos soldados, fueron enviados de regreso a Esparta para unirse indiscriminadamente con las doncellas ${ }^{18}$; es sintomático que Éforo no mencione a Falanto ni a ningún otro líder de los partenias. Heráclides Lembo (Exc. Pol. 57 Dilts), sin especificar la guerra mesenia, refiere que en ausencia de sus maridos las mujeres dieron a luz niños que los padres sospechaban que no eran suyos, razón por la cual los llamaron partenias, pero estos no lo soportaban. Una última tradición hace a los partenias hijos

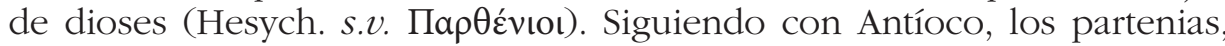
que alcanzaron cierta importancia numérica (toda una generación) ${ }^{19}$, se organizaron para tomar parte en un golpe de Estado bajo el liderazgo de Falanto, aprovechando la celebración de las fiestas Jacintias en Amiclas ${ }^{20}$.

una falsa etimología, un intento tardío de explicar una designación de los colonos cuyo significado real se nos escapa; algunos se arriesgan a aventurar una respuesta: Philippides (ibid.) propone, por ejemplo, que podría aludir a "bajo la protección de la parthenos (Ártemis)", recordando la hipótesis de Wuilleumier (ibid.) de que podría tratarse de Polibea, la hermana de Jacinto, asimilada a Ártemis (y también a Perséfone), pero ni los argumentos de uno ni los del otro son convincentes. En cualquier caso, es seguro que se trataba de un grupo segregado del cuerpo cívico lacedemonio.

16. Según ha hecho notar Moscati Castelnuovo, «Iloti», 69, no deja de ser una incongruencia que descendientes de hilotas puedan ser considerados atimoi y ser llamados partenias.

17. Moscati Castelnuovo, «lloti», 75-77; Bogino, "Margine», 12-13.

18. Como recuerda Nafissi, Nascita, 40, este relato abunda en el estereotipo de la licenciosidad de la mujer espartana, bien asentado ya en época de Éforo. De nuevo hay una contradicción en que las uniones mixtas fueran contempladas como una solución al problema de escasez de ciudadanos, pero finalmente no generen ciudadanos (cf. Corsano, «Sparte», 121-122; Parker, "Dates», 29-30, quien enfatiza asimismo lo inverosímil de que los espartiatas no hubieran regresado a casa cada invierno durante esa década, período por lo demás evocador de la guerra de Troya; pero, en su interés por eliminar toda conexión con la primera guerra mesenia, Parker hace a los partenias hijos bastardos de homoioi con mujeres hilotas y periecas).

19. Esto no significa, como quiere Qviller, "Reconstructing", que debamos leer la historia de la fundación de Taras única y exclusivamente a la luz de la agoge, como un rito de iniciación a la edad adulta de los jóvenes colonos.

20. Puesto que el culto a Apolo Jacintio fue exportado desde Esparta a Tarento, se ha considerado que los colonos pudieron proceder de la oba de Amiclas (Wuilleumier, Tarente, 42-45; Pugliese Carratelli, "Storia», 134-139; Cartledge, Sparta, 124; Moscati Castelnuovo, 
Aristóteles, que cita la conspiración como ejemplo de aquellas urdidas por un número considerable de individuos que no se consideran inferiores en virtud, afirma que los partenias eran $\dot{\varepsilon} \kappa \tau \tilde{\omega} v$ ó $\mu \mathrm{o} \omega \nu v$, esto es, hijos de los homoioi (Pol. 1306b28-29). Una fuente tardía como Justino (3.4.8) nos dice que los partenias, sin padre reconocido, carecían de herencia y de medios para la subsistencia al llegar a los treinta años ${ }^{21}$.

El ataque debía comenzar en el momento en que el prostates se ciñera su $\kappa v v \tilde{\eta}$ (en Aen.Tact. 11.12 y Polyaen. Strat. 2.14.2 la señal consistía en levantarlo), el gorro de piel de perro que caracterizaba a los hilotas (cf. Mirón de Priene FGrH 106 F2 apud Ath. 657d), pese a que recordemos que los partenias no eran esclavos (en la versión eforea se trata de un $\pi \tilde{\lambda} \lambda o s$

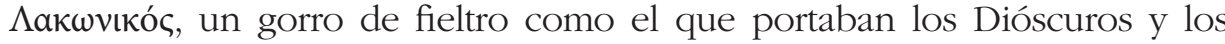
guerreros espartiatas) ${ }^{22}$, pero el complot es denunciado y abortado. Se decide entonces enviar a los partenias a fundar una colonia, ya que debe expiarse el acto execrable de fomentar la stasis y promover una insurrección, de haber llevado el temido miasma a la comunidad al igual que sucede con un asesinato (cf. Pl. Leg. 856b) ${ }^{23}$. Antes de partir, Falanto fue

"Iloti», 64-68); esta conexión con Amiclas también ha sido planteada por Valdés Guía, «El culto de Afrodita", pero más sobre la base de rituales a Afrodita armada (compatibles con el papel de Apolo y Jacinto). Las Jacintias son una fiesta que integra de forma organizada, por grupos y no individualmente, a toda la sociedad lacedemonia, pero que sin duda adquiere su sentido más prístino en el marco de la transición a la edad adulta de los efebos y doncellas espartiatas, revestida de elementos agonísticos y que tiene a la pareja Apolo y Jacinto, dios y héroe, como veladora y garante de tan transcendental paso en la vida del ser humano (véase ahora Fornis, "Celebrando").

21. Trogo, a través de Justino, es la única fuente que precisa el hecho de que los partenias se encontraban en el momento en que la polis define que el joven deja de serlo para pasar a la edad adulta, cuando, de no carecer de legitimidad, accedería a la ciudadanía plena; se pone así de manifiesto que «las fundaciones griegas obtienen a sus futuros ciudadanos de los descontentos de la metrópolis, de los marginados en el proceso de conformación del sistema de la polis» (Domínguez Monedero, "Phocaeensium», 67, enmarcando el caso de los partenias en el contexto de diversas tradiciones coloniales).

22. Diod. Sic. 8.21.1 presenta a un Falanto armado que da la señal quitándose el casco (como el Siciliota suele basarse en Éforo, se suele enmendar la frase). Esto indicaría, según Maddoli, "Falanto", 560, disposición al combate y que Falanto era un espartiata de pleno derecho (pero la tesis del estudioso italiano de que era protector o patrono de los partenias sin liderar al mismo tiempo la conspiración es poco convincente; cf. la refutación del análisis filológico y factual a cargo de Musti, "Ruolo», 862-865). Para la contraposición pilos-kyne como reflejo de la dualidad de tradiciones sobre los orígenes y condición de los partenias, véase asimismo Valdés, "El culto a Zeus", 309-311, dentro de su argumentación (305-314) de que los colonos tendrían un estatuto hilótico e instaurarían un culto a Zeus Eleutherios en el ágora tarentina desde la fundación misma de la ciudad.

23. Cf. Dougherty, «Murder», 182: "A efectos de representaciones de colonización, el modelo de un exilio político es estructuralmente similar al de un asesino que debe huir de su ciudad". 
a consultar al santuario de Delfos. La pitia, conforme a las palabras de Antíoco, vía Estrabón, declaró:

Yo te concedo Satirio,

habitar los parajes de la feraz Tarento

y convertirte en el azote de los yápiges ${ }^{24}$.

Finalmente, Falanto y sus partenias partieron hacia la península itálica, pero en lugar de tomar la "tierra prometida" por la fuerza y esclavizar a los bárbaros que la ocupaban, como hubieran hecho los espartiatas, se asentaron y convivieron pacíficamente con ellos, algo más propio de los descendientes de hilotas que eran (en Éforo, en cambio, donde no aparece el oráculo, los partenias "honran" su sangre espartiata luchando y venciendo a los indígenas $)^{25}$. Aunque en el área de Satirio, la acrópolis tarentina situada en la costa, los restos materiales griegos se sobreponen a los de los yápiges autóctonos ${ }^{26}$, recientes y sistemáticos trabajos arqueológicos de la Universidad de Ámsterdam en el istmo salentino (entre Tarento y Bríndisi) parecen desmentir un ambiente, por lo menos continuado, de hostilidad y enfrentamiento entre colonos e indígenas, y nos hablan por el contrario de cohabitación. Por ejemplo, el bien estudiado hábitat de L'Amastuola, en el hinterland tarentino (a unos $15 \mathrm{~km}$ al noreste de la colonia griega), muestra a finales del siglo VIII y en el VII una identidad cultural híbrida y una cultura material mixta; la situación cambiaría en la primera mitad del siglo V, cuando L'Amastuola y otros enclaves salentinos experimentaron importantes alteraciones en la organización de los asentamientos y las necrópolis, así como en el uso de la tierra, consecuencia de la expansión de Tarento y de la integración en su chora $^{27}$.

En el relato que nos ofrece Diodoro de Sicilia (8.21.1) los partenias parecen compartir conspiración con los epeunactoi, literalmente

24. Trad. J. Vela Tejada. Parke y Wormell, Delphic Oracle, II, n. ${ }^{\circ} 47$. Satirio se encuentra a $12 \mathrm{~km}$ al sureste de Tarento (sobre todo lo que concierne al topónimo, véase Arena,

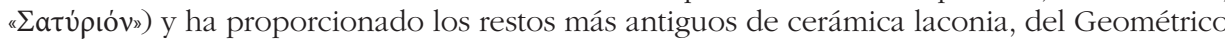
Tardío (sobre las excavaciones: Lo Porto, «Satyrion»), por lo que pudo ser un lugar temporal de los colonos antes de ocupar de manera definitiva la más privilegiada Tarento (Lo Porto, "Topografia», 357). Nenci, "Bá $\rho \beta a \rho o{ }^{\prime}$ ", 731, y Russo, "Donari», 79, creen que el oráculo representa a Tarento como baluarte de la helenicidad en un contexto de barbaros polemos en la zona del Salento, pero véase Lombardo, "Tombe», para un análisis más detallado de las dinámicas de interacción entre colonos y yápiges-mesapios en el marco de distintos procesos de construcción, representación y transformación de la identidad tarentina.

25. Nafissi, "Sparta", 254

26. Cf. De Juliis, Taranto, 15-19.

27. Burgers, «Identità»; Burgers y Crielaard, "Greek Colonists», «Mobilità», «Migrant's»; Crielaard y Burgers, "Communicating», «Greek Colonists». 


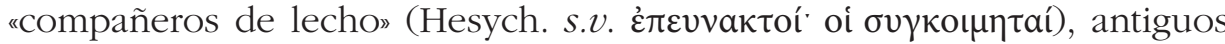
hilotas que, según Teopompo (FGrH 115 F171 apud Ath. 271C-D), habrían ganado la libertad y la ciudadanía debido a las necesidades generadas por las bajas en combate entre los homoioi $i^{28}$; que la integración en la comunidad cívica no fue completa lo testimonia su designación infamante y el recuerdo de su implicación en esta revuelta social, aunque es muy posible que el historiador siciliota esté confundiendo aquí a epeunactos y partenias (de hecho, en 15.66.3 solo menciona a los partenias en la ktisis de Tarento, mientras que otra entrada del léxico de Hesiquio equipara a partenias y eneunactos, una variante de epeunactos: Hesych. s.v.

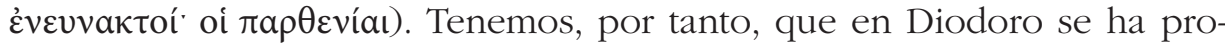
ducido una inversión con respecto al relato de Antíoco, el más antiguo: en vez de espartiatas degradados, nos encontramos hilotas promocionados, liberados tras su servicio militar, aunque tampoco integrados en el cuerpo cívico ${ }^{29}$. Persiste, como sustrato común a estas tradiciones, la inferioridad de los futuros colonos respecto de los espartiatas originales ${ }^{30}$. Una vez que Falanto y sus seguidores desistieron de materializar su golpe, habrían sido los propios epeunactos — en realidad los partenias- quienes enviaron embajadores a Delfos para obtener su beneplácito a la idea de asentarse en el territorio de Sición, dando lugar a un oráculo cronológicamente anterior al ya citado, el cual fue necesario, según Diodoro, porque este no fue entendido:

La tierra entre Corinto y Sición es en verdad hermosa; pero no la habitarás, aunque todo de bronce vistas.

Tú mira a Satirio y a la brillante agua de Tarento,

28. De una etimología oscura, se ha propuesto que los epeunactos fueran hilotas admitidos por las mujeres espartanas para reemplazar en el tálamo a sus esposos caídos en el conflicto (Paradiso, "Epeunatti", que postula que se trata de un rito iniciático y que los manumisos desposarían también a las viudas de los espartiatas), o bien hilotas que han sustituido valerosamente a los espartiatas en los lechos de campaña (así Pembroke, "Femmes", 1246-1249, y Malkin, Myth, 141 n. 147, para quienes pudieron ser los padres de los partenias; Musti, "Ruolo», 870-871). Según Nafissi, Nascita, 41-51, son evidencia en cualquier caso de formas de integración social favorecidas por las necesidades bélicas y basadas en procedimientos jurídicos desconocidos.

29. Wuilleumier, Tarente, 39; Moscati Castelnuovo, «Iloti», 77-79; Nafissi, Nascita, 50 (dependientes, más que hilotas, en una sociedad que aún trazaba de manera difusa los límites entre libertad y esclavitud).

30. Como ya expresaran Bérard, Colonisation, 168-169; Cartledge, Sparta, 123, o Sakellariou, Memory, 80-81, 90-91, la impureza en el nacimiento, común a todas las fuentes, merece consideración. Una posición hipercrítica es la de Kennell, Spartans, 35-36, que despoja de toda credibilidad a las fuentes y concluye de sus relatos: "Can any sense be made of this?». Pero ya Dunbabin, Western, 90, tildaba de fabulosas las noticias sobre los partenias. 
un puerto a la izquierda, y el lugar donde el macho cabrío su afecto muestra a la salada ola del mar, mojando el extremo de su barba gris. Haz allí una Tarento firme en tierra de Satirio ${ }^{31}$.

En lugar del territorio entre la Corintia y la Siciónide, en un primer verso que llegó a ser proverbial sinónimo de prosperidad y riqueza ${ }^{32}$, el dios les ofrece Tarento, ciudad que debía ser levantada en un lugar descrito en relación a un puerto y a un macho cabrío que gusta de beber agua salada. El adynaton o imposibilidad de que esto último suceda se disipa si se acepta la explicación de Dionisio de Halicarnaso (19.1.4) de que, en uno de los habituales juegos de palabras délficos, трáyoc no tiene aquí el significado más habitual y difundido de macho cabrío, sino el que adopta entre los mesenios -y aquí hay descendientes de hilotas implicados-, el de higuera salvaje. Tanto el macho cabrío, por su proverbial apetito sexual (basta pensar en la figura del sátiro), como el higo

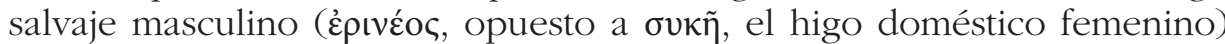
son metáforas de la fecundidad masculina, de tal forma que las ramas plateadas de la higuera harían las veces de la barba del chivo, que al introducirse en el mar lo fertilizan, siendo el puerto metáfora de la sexualidad femenina; por lo demás, la alta e indiscriminada polinización de la higuera salvaje podría entenderse como una alusión a los desconocidos progenitores paternos de los partenias $^{33}$. Estos paisajes imposibles pero a la vez genuinos son comunes entre los oráculos coloniales. Como ha concluido Carol Dougherty, "las estrategias de representación inherentes a los acertijos, el componente de ambigüedad que comparten las leyendas de colonización y el lenguaje de los oráculos délficos y el énfasis sobre la interpretación, pueden haber influenciado la (retrospectiva) incorporación de los oráculos délficos dentro de las tradiciones coloniales tanto como la costumbre de consultar el oráculo antes de la colonización» ${ }^{34}$.

El hecho de que el oráculo otorgara a los colonos indicaciones topográficas tan precisas, dirigiendo al fundador al lugar exacto en el que

31. Trad. J. J. Torres Esbarranch ligeramente modificada. Parke y Wormell, Delphic Oracle, II, n. ${ }^{\circ} 46$.

32. Maurizio, Delphic Narratives, 133; Lippolis, Garraffo y Nafissi, Culti, 300.

33. Dougherty, «Rain», 35 con n. 24 y Poetics 49-50, 73-74; Maurizio, Delphic Narratives, 133-136. Para Lippolis, Garraffo y Nafissi, Culti, 300-301, el oráculo, más que entroncar con la tradición mesénica, describe el Mar Piccolo en relación con el puerto y la acrópolis de Tarento (aduciendo que quizá Dionisio ignorara la equivalencia entre Satirio y Tarento); también rechaza la interpretación "botánica" Arena, "Latúpıóv», 269, que ve en tragos una alusión a Satirio "por la vía del aspecto caprino del sátiro" y cree que la forma de la acrópolis podría recordar la barba de un chivo.

34. Dougherty, «Rain», 41. 
debía levantar la nueva ciudad, ha provocado cierto debate historiográfico en torno a su autenticidad y su antigüedad ${ }^{35}$. Parke y Wormell primero y Malkin casi cuatro décadas más tarde concedieron crédito a la veracidad de la profecía en fecha temprana (c. 710), basándose en el retruécano, la descripción geográfica y la toponimia ${ }^{36}$. Fontenrose negó su autenticidad argumentando, por un lado, que en aquel entonces Delfos aún no había adquirido reputación como centro oracular a nivel panhelénico y, por otro, que Falanto es la hipóstasis del héroe Palemón ${ }^{37}$. Más recientemente, el análisis de la lengua poshomérica utilizada en los dos oráculos en hexámetros ha llevado a Suárez de la Torre a la conclusión de que se remontan, como mucho, al siglo VI, con un colorido épico que trasluciría un intento del autor de contribuir a la heroización de Falanto, devenido un nuevo Aquiles $^{38}$. Lo cierto es que este argumento de la composición métrica, sumado a los anacronismos (la inclusión del puerto en la topografía tarentina y el contexto de contraposición y conflicto entre helenos y bárbaros que caracterizará el final del siglo VI y primer tercio del V) y a que, como hemos dicho más arriba, se hace difícil aceptar un procedimiento regulado de consulta oracular en Delfos por los colonos ya a finales del siglo VIII, nos llevan a considerar ex eventu los oráculos sobre la fundación de Tarento ${ }^{39}$.

En cualquier caso, Falanto pasaría a la posteridad como héroe fundador del nuevo asentamiento y el relato de sus peripecias ha perdurado con inusitado vigor en la historia local tarentina hasta nuestros días, tanto

35. Sobre esta problemática en general, véase Malkin, Religion, 50; Domínguez Monedero, "Oráculos", 75. En todo caso, Maurizio, "Delphic Oracles», 312, advierte que "del mismo modo que no se pueden recuperar los versos homéricos originales, no existe oráculo de la tradición délfica que pueda ser demostrado como tal».

36. Parke y Wormell, Delphic Oracle, I, 72-73, matizando que «si el oráculo es falso, al menos no debe de ser de fecha tardía; Malkin, Myth, 121-122.

37. Fontenrose, Delphic Oracle, 140-141. Para otros autores Falanto sería la hipóstasis de Posidón (Giannelli, Culti, 12-13), de Apolo Delfinio/Apolo Jacinto (Wide, Lakonische, 87-88; Wuilleumier, Tarente, 47), de algún héroe mesapio (Studniczka, Kyrene, 191 y ss.) o del dios delfín de los cretenses (Defradas, Thèmes, 237 n. 1), planteamientos hoy superados (cf. Lippolis, Garraffo y Nafissi, Culti, 293).

38. Suárez de la Torre, "Oracoli», 28-33.

39. Además de los ya citados Fontenrose y Suárez de la Torre (supra nn. 37 y 38), los consideran también retrospectivos Lippolis, Garraffo y Nafissi, Culti, 299-302; Arena,

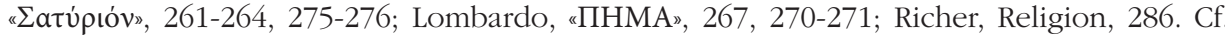
Sakellariou, Memory, 75: "All the relevant oracular texts quoted by these authors are imaginary»; Esposito, "Identités», 228-229: «Nous devrions peut-être utiliser davantage les oracles en fonction du temps historique dans lequel ils sont transmis». 
como para servir incluso de inspiración a poemas ${ }^{40}$. Una de las características del fenómeno colonizador griego del Arcaísmo radica en que, al resolver los acertijos y juegos de palabras que el oráculo délfico plantea sobre la potencial fundación, los oikistai eran caracterizados como líderes competentes y conocedores del entorno en el que se va a levantar su ciudad y, por tanto, merecedores de llevar a cabo la empresa ${ }^{41}$. Este aspecto, que ya se encontraría presente en el vaticinio del que nos informa Diodoro, aparece asimismo en otra tradición, sin duda posterior ${ }^{42}$, que nos ofrece Pausanias (10.10.6-8). El Periegeta revela que el oikistes (cuyo nombre, $\Phi a ́ \lambda a v \theta o \varsigma$, significa literalmente "calvo» y, por tanto, desprovisto de la melena que caracterizaba a los homoioi o ciudadanos de pleno derecho) ${ }^{43}$ recibió un oráculo délfico según el cual «cuando percibiera una lluvia bajo el cielo sereno, entonces adquiriría una región y una ciudad» (v́ctoṽ

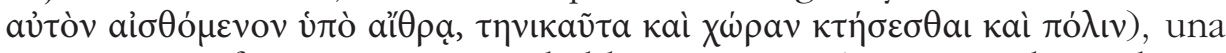
circunstancia francamente improbable que terminó provocando su desesperación. Fue entonces cuando su mujer, Etra (otro nombre parlante que, precisamente, significa "cielo azul", "cielo sereno") $)^{44}$, compadeciéndose de Falanto, derramó lágrimas sobre él mientras lo despiojaba, aclarando el verdadero sentido de tan ambiguo oráculo ${ }^{45}$. La noche siguiente, concluye el Periegeta, los yápiges fueron sometidos y los partenias se apoderaron de Taras. Plutarco (Mor. 407f-408a) refrenda que Falanto supo interpretar bien los signos. Pero ¿cómo es posible que un personaje que adolece de

40. Nos referimos a la Canzone di Falanto, poema en endecasílabos compuesto por el profesor Fulvio Volpi a partir del pasaje pausaniano (10.10.6-7) y reproducido en Presicci, Falanto, 68-71, librito por lo demás escrito por un médico tarentino que, pese a su enjundioso título, es un ejemplo de uso totalmente acrítico de las fuentes en aras de realzar entusiásticamente la "historia patria».

41. Dougherty, "Rain», 39-40.

42. Nafissi, «Sparta», 256-257 con n. 81.

43. Sobre la estética visual del cabello en la sociedad espartiata, cargada de simbolismo, véase David, "Sparta's".

44. Lippolis, Garraffo y Nafissi, Culti, 290, descartan la sustancia religiosa de este personaje y (pace Giannelli, Culti, 12) cualquier identificación con la deidad celeste que, junto a Posidón-Egeo, engendró a Teseo. De hecho, el caso de Etra es una excepción a la norma de que los fundadores viajaban sin acompañamiento familiar, aunque su papel aquí es instrumental para el descubrimiento accidental de la localización de Taras (cf. McGlew, Tyranny, 169 n. 29). Para Dunbabin, Western, 30 n. 5, «esta estúpida historia es un buen ejemplo de oráculo fundacional ahistórico", mientras que para Lacroix, "À propos des offrandes», 172, «tiene el aire de un acertijo para entretener a los niños».

45. Para una comparación con otra fábula similar, la de Miscelo y el oráculo que guio la fundación de Crotona, cf. Goegebeur, «Myskellos». 
calvicie pueda ser despiojado? ${ }^{46}$. Porque, en la versión de la que se sirve Pausanias, Falanto había dejado de ser un marginado y compartía simbólicamente las virtudes de los espartiatas de pleno derecho. El proceso hacia la heroización del oikistes se había completado ${ }^{47}$ y Falanto y Etra habían quedado indisolublemente unidos a las historias que circulaban por el santuario de Delfos y que eran contadas a sus visitantes ${ }^{48}$.

Por otra parte, Falanto comparte la condición y los honores de fundador con Taras, epónimo - un epónimo pasivo - de la ciudad y de su río (Paus. 10.10.8; cf. Dion. Hal. 19.1.3), hijo de Posidón y de una ninfa local llamada Satiria ${ }^{49}$ (en otra versión Satiria es hija del mítico rey cretense Minos $)^{50}$. Tenemos una extraña $-\mathrm{y}$ por momentos difusa- dualidad o dicotomía entre héroe autóctono y héroe alóctono a la hora de reclamar la autoría del acto fundacional, ambos casos siendo de culto público, pero respaldados por realidades sociales diferentes (vid. infra) ${ }^{51}$. Fuentes tardías como Servio (ad Georg. 4.125; ad Aen. 3.551 y 6.773), Probo (ad Georg. 2.197) e Isidoro (Etym. 15.1.62) intentan solventar la discrepancia afirmando que Taras fue el fundador de la ciudad y que Falanto la engrandeció (Taras condiderat, auxerat Phalantus dice, por ejemplo, el poeta Servio en ad Aen. 3.551) ${ }^{52}$.

Pausanias (10.13.10) cuenta que, después de haber recibido la orden délfica de zarpar hacia Taras, Falanto habría naufragado en la zona del golfo de Crisa y habría sido rescatado por un delfín, a cuyo lomo pudo llegar hasta su destino. De hecho, el Periegeta vio en Delfos, colocado

46. El tema del sollozo y del despiojamiento tiene amplios ecos en el folclore popular (cf. Goegebeur, "Aithra», 66; Nafissi, «Sparta», 257).

47. Al igual que Dunbabin, Western, 30; Bérard, Colonisation, 171; Lacroix, Monnaies, 90 (reafirmado en "À propos des offrandes", 173-174); Corsano, "Sparte», 130-133; Malkin, Religion, 216-221, y Sakellariou, Memory, 81-82, pensamos que Falanto es en origen un personaje histórico, el fundador real de la colonia; contra Pembroke, "Femmes», 1259-1265, que rechaza su historicidad; para Giannelli, Culti, 8, o Lippolis, «Testimonianze», 95, se trata de una figura pseudohistórica.

48. Lacroix, "À propos des offrandes", 172

49. Y epónima de Satyrion, que una tradición clásica y helenística hará el territorio antiguo - -y más concretamente la acrópolis_ de Tarento, luego integrado como $\chi \omega ́ p a$ en la polis tarentina (cf. Lippolis, Garraffo y Nafissi, Culti, 291-292).

50. En otra tradición, originada probablemente en el siglo IV a. C., Satiria es la mujer de Taras y de esta unión nace Ítalo (Nafissi, "Rapporti», 314-315, subraya su importancia para el concepto geográfico de Italia).

51. Lippolis, «Testimonianze», 93, habla de una auténtica reduplicación de la ktisis de la ciudad; para Esposito, "Identités", 229, «el recurso a un doble ecista es la consecuencia de una doble memoria (la griega y la local)».

52. Lacroix, "À propos des offrandes", 174, acepta tal posibilidad, recurriendo al ejemplo de Metaponto. 
en un lugar prominente del Altis - frente al templo de Apolo y junto a la columna que conmemoraba la victoria en Platea-, un grupo escultórico ofrendado por los tarentinos en el tercer cuarto del siglo $\mathrm{V}$ a. C. con el botín capturado a sus enemigos indígenas, obra del egineta Onatas y de otro escultor - para el que se han propuesto varias restituciones-53, en el que se representaba a los dos héroes, cuya epifanía en la batalla había otorgado la victoria, junto a un delfín:

[...] Son estatuas de infantes y de jinetes, y Opis, rey de los yápiges, que había venido como aliado de los peucetios. Éste está representado como muerto en la batalla, y junto a su cadáver están el héroe Taras y Falanto de Lacedemonia; y no lejos de Falanto hay un delfín [...]. ${ }^{54}$

En el campo numismático, donde la evidencia es escasa y controvertida, se han hecho grandes esfuerzos por identificar a Falanto con el personaje desnudo que cabalga sobre el delfín en el anverso de las estáteras tarentinas en plata que se acuñan sin interrupción desde finales del siglo VI hasta la captura de la ciudad por Roma en 2095. Sin embargo, en un fragmento de su Tarantinon Politeia Aristóteles (fr. 590 Rose = Poll. Onom. 9.80) afirma que el representado en las monedas es Taras, no Falanto. No es convincente la hipótesis ${ }^{56}$ de que la leyenda TAPA $\Sigma$, referida a la ciudad y no al delfiniere, indujo al error al Estagirita, que sin duda transcribía una fuente tarentina. Lo cierto es que ambos héroes parecen confundirse en su convivencia en el imaginario mítico tarentino ${ }^{57}$, tanto como para

53. Resumidas por Esposito, "Identités", 220.

54. Trad. de M. ${ }^{a}$ C. Herrero Ingelmo. Sobre el grupo escultórico, uno de los dos àväń $\mu a \tau a$ tarentinos contra los bárbaros descritos por Pausanias, así como para su contexto histórico, véase Amadry, "Notes»; Nenci, "Bápßapo̧»; Beschi, «Donari»; Lippolis, "Testimonianze», 96-97; Lacroix, «Ä propos des offrandes», 171-174; De Juliis, Taranto, 21-24; Russo, "Donari»; Esposito, "Identités».

55. Sobre esta iconografía monetal y otras emisiones tarentinas que tendrían como tipo a la divinidad fluvial epónima, cf. Lacroix, "Sur quelques offrandes", 14-23, y Monnaies, 89-100; Carroccio, «Iconografie», 124-125, habla de una deidad heroico-ctónica común para toda el área mesapia que asumiría diferentes nombres según las ciudades (en Tarento identificándose con Taras); para Corrado, "Nuova", el delfiniere no es otro que Apolo Pitio en su papel de ecista, levantando el brazo para guiar a los colonos.

56. Malkin, Religion, 219, y Myth, 137-138, aunque ya lo planteó Bérard, Colonisation, 170 con n. 7.

57. Retomando la sugerencia de Studniczka, Kyrene, 175-194, que ha gozado de gran fortuna entre los estudiosos (inter alia Giannelli, Culti, 10-11; Wuilleumier, Tarente, 37-38, y Malkin, Religion, 219-220, y Myth, 137-138), Lippolis, Garraffo y Nafissi, Culti, 295, sospechan un "Scambio mitico, e conseguentemente iconografico" acaecido entre la época de Onatas y la de Aristóteles. Giannelli, Culti, 9 prefería hablar de "préstamo del patrimonio mítico de uno a otro». Lacroix, Monnaies, 90, 93-96 descartaba a Falanto porque para él 
que en tradiciones tardías y nada atendibles Falanto sea considerado hijo de Neptuno y Taras descendiente de Hércules ${ }^{58}$. Prueba significativa de la maraña de tradiciones que se fue entretejiendo con el paso del tiempo, como parte de una dialéctica continua entre pasado y presente que inviste la memoria de los orígenes ${ }^{59}$, es el relato en el que Probo (ad Georg. 2.198) cuenta que eel lacedemonio Taras [sic], hijo de Neptuno, tuvo un hijo de Satiria, hija del rey cretense Minos; éste ${ }^{60}$, expulsado de la ciudad y habiendo sufrido naufragio, fue salvado por un delfín que le llevó a Italia». Personajes asociados a delfines o que cabalgan sobre ellos son frecuentes en el folclore heleno - Arión de Lesbos es el más conocido-, particularmente en el relacionado con Apolo ${ }^{61}$, pero el de Posidón no es ni mucho menos ajeno. Falanto tenía ese vínculo con Apolo, mientras Taras lo tenía con Posidón, la divinidad políada de los tarentinos, así que no resulta extraño que el delfín pueda ser conectado a uno u otro héroe, máxime cuando la iconografía de Taras le representa bajo forma humana y no con los rasgos o atributos propios de una divinidad fluvial ${ }^{62}$. No obstante, la historiografía moderna ha tratado de acomodar la fortuna de ambos a la evolución política de Tarento, de tal modo que se tiende a reconocer un período inicial de auge de Falanto, al socaire del ordenamiento aristocrático de corte espartano implantado por los $\operatorname{colonos}^{63}$, con una fuerte oposición al elemento indígena que se plasma en el oráculo que les vaticina convertirse en $\pi \tilde{\eta} \mu \alpha$ 'Ia $\operatorname{có} \gamma \varepsilon \sigma \sigma \mathrm{l}$ —de reminiscencias homéricas (Il. 12.416423) y con eco en el verso "habiendo respondido a la lanza de los yápiges» de Calímaco (fr. 613 Pfeiffer)—; sigue un cierto eclipse ideológico y

"pertenece al dominio de la historia y no al de la leyenda" y, consecuentemente, hubiera sido una anomalía representarlo; el numísmata belga ya había planteado antes («Sur quelques offrandes", 20-23), y volvería a hacerlo casi cuatro décadas después ("À propos des offrandes", 173-174), que el delfín, desvinculado de su jinete, era el auténtico emblema de la ciudad y solo después emergería la "fábula" de la salvación milagrosa de Taras en el naufragio. Recientemente Corrado, "Nuova», seguida por Esposito, "Identités», 226-227, se ha opuesto a esta hipótesis de "numismatici della vecchia scuola" y ha avanzado la de que se trataría de Apolo Pitio, heredero de las competencias del más antiguo Apolo Delfinio.

58. Lippolis, Garraffo y Nafissi, Culti, 298-299.

59. Lippolis, Garraffo y Nafissi, Culti, 156.

60. Puesto que parece evidente que el hijo de Taras y Satiria no es el protagonista del naufragio en Italia, Lippolis, Garrafo y Nafissi, Culti, 296, seguidos por Arena, "Latúpióv», 256 n. 9, han supuesto que falta texto que no sería del interés del comentarista.

61. Lacroix, "Sur quelques offrandes", 20, pensaba de hecho que la leyenda del naufragio se había originado en Delfos.

62. Lippolis, Garraffo y Nafissi, Culti, 295.

63. No obstante, Alessandrì, "Phalantiadi», ha demostrado que no es atendible la noti-

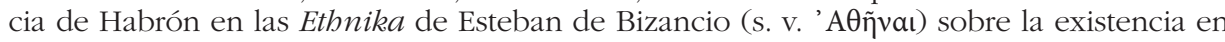
Tarento del genos de los Falantíadas, descendientes del fundador. 
religioso de Falanto en contrapartida a un ascenso de Taras, coincidente con el período democrático que se abre en el segundo cuarto del siglo V, de crecimiento demográfico de la ciudad y de reivindicación de las raíces indígenas - Taras encarna al conjunto de los tarentinos, no solo a un estrato social determinado-; se asistiría por último a una revigorización de la figura de Falanto en los años en que Tarento solicita y consigue la ayuda militar de varios condottieri provenientes de la metrópoli ${ }^{64}$.

La leyenda en torno a Falanto y su vinculación con el santuario de Delfos se extiende hasta el momento mismo de su muerte. De acuerdo con el testimonio de Justino (3.4.12-18), el oikistes fue desterrado por sedición de la colonia que había fundado y se retiró a Brentesion (Bríndisi), donde, consciente de la proximidad de su fin, convenció a los yápiges para que incinerasen su cuerpo y esparcieran en secreto sus cenizas en el ágora de Taras desvelando un oráculo délfico que vaticinaría que de este modo los indígenas recuperarían la posesión de su territorio patrio. Sin embargo, el verdadero significado del oráculo, según el epitomista, radicaría en que mediante la dispersión de las cenizas de Falanto sobre su propia ciudad se garantizaría para siempre la posesión tarentina del territorio conquistado. Los habitantes de la colonia, agradecidos, otorgarían desde entonces honores divinos a Falanto.

No conocemos con exactitud en qué momento surgió esta tradición, pero parece claramente una invención tardía, la culminación de la transformación heroica de un personaje cuyo viaje iniciático había comenzado en el ámbito de la marginación ${ }^{65}$; de paso, podría explicar la ausencia de tumba o cenotafio del ktistes en el ágora tarentina ${ }^{66}$. El relato sobre la muerte de Falanto se moldea sobre el de la muerte de Licurgo, fundador a su vez del cosmos espartano, quien, fiel a la proverbial astucia lacedemonia, se habría dejado morir de hambre — en Delfos nada menos - tras haber hecho jurar a sus conciudadanos antes de partir al exilio que no cambiarían sus leyes hasta su regreso (Just. Epit. 3.3.11; Plut. Lyc. 29.1-9) y cuyas cenizas también fueron esparcidas, en este caso por el mar (Just.

64. Wuilleumier, Tarente, 38; Malkin, Myth, 138-139; Lippolis, «Testimonianze», 93-97; Lippolis, Garraffo y Nafissi, Culti, 295-296; Nafissi, «Rapporti», 316-319; Esposito, "Identités», 227-228. Hay quien hace el viaje a la inversa, como Gasperini, "Cultos", 156, que ve en la toponomástica la confirmación de que Taras fue un héroe más antiguo que Falanto en la mitología tarentina.

65. Véase Corsano, «Sparte», esp. 132, seguida por Lombardo, «Tombe», 40, quien añade que tal tradición se nutre de la idea, presente en distintas fuentes, que hace de Falanto no tanto un fundador como un conquistador de Tarento. Cf. también Sakellariou, Memory, 83-84, que no parece conocer (o no cita) a los anteriores.

66. Así Malkin, Religion, 217-218, y Myth, 132-133; cf. Lombardo, «Tombe», 40. 
Epit. 3.3.12; Plut. Lyc. 31.10) ${ }^{67}$. Ambos fueron reconocidos como personajes que trascienden su condición mortal para asumir la heroica y crear, a su manera, un nuevo orden sociopolítico en sus respectivas comunidades. Más importante aún, el oráculo de Delfos aprobó y sancionó sendas iniciativas $^{68}$

Al margen de su más que cuestionable veracidad, el relato de la fundación de Taras se ajusta al patrón narrativo del movimiento colonizador griego del Arcaísmo. En primer lugar, debe producirse una crisis cívica en la ciudad de origen. En nuestro caso, Esparta se ve sumida en una larga guerra que acarrea problemas sociopolíticos directamente relacionados con la configuración del mismo Estado como polis. La inestabilidad provocaría posteriormente la consulta, por parte de una de las facciones, al oráculo de Delfos para seguir un destino separado al de su patria y Apolo, en consecuencia, otorgaría una profecía autorizando la fundación de una nueva ciudad en ultramar. El éxito en la empresa colonial proporcionaría finalmente la resolución de la crisis originaria, convirtiéndose el fundador de la ciudad y otrora peligro social en objeto de veneración o culto ${ }^{69}$.

A la hora de establecer conclusiones, no estará de más recordar la sabia advertencia de Massimo Nafissi en cuanto a que "las historias de fundación no son reflexiones "históricas» de los hechos reales en torno al asentamiento, sino una ficción basada en acciones, personajes y tiempos de la histoire événementielle ${ }^{70}$. Es inútil, por tanto, intentar una reconstrucción histórica de lo acontecido ${ }^{71}$. Pero sí podemos, como recomendaba Marinella Corsano, escudriñar ese entramado mítico a la luz de la sociedad que lo ha producido ${ }^{72}$. En nuestro caso, más allá de lo que las brumas de la leyenda, los retazos de tradiciones orales y las artificiosas e interesadas construcciones historiográficas nos permiten atisbar, el

67. Aunque la práctica de dispersar cenizas y restos óseos en el ágora es ajena al horizonte cultural heleno, Lombardo, «Tombe», 38-39, subraya que se inscribe bien en prácticas cultuales e ideológicas arcaicas del área mesápica. También una tradición que se remonta al menos al siglo V aseguraba que las cenizas de Solón, otro famoso legislador que sufrió el exilio, fueron esparcidas por su querida isla de Salamina (Plut. Sol. 32.2; Val. Max. 5.3 ext. 3; Aristid. Or. 46.172)

68. Malkin, Myth, 129-131.

69. Sobre esta distinción en fases del modelo narrativo de la colonización arcaica, cf. Dougherty, Poetics, 15-30.

70. Nafissi, "Sparte», 252.

71. Es encomiable el intento de Sakellariou, Memory, 66-93, esp. 90-91, que trata de deducir de una forma razonada qué hay de histórico y qué de imaginario en cada una de las fuentes con la finalidad de construir un relato coherente e inteligible (pero que no deja de ser altamente especulativo).

72. Corsano, «Sparte», 113-114. 
episodio de los partenias revela las graves tensiones generadas por las reivindicaciones de acceso a la politike chora $-\mathrm{y}$ al disfrute de los derechos políticos y socioeconómicos que conlleva- por parte de determinados grupos en un momento en que aún se estaba configurando el politeuma lacedemonio, quiénes lo integraban y qué derechos poseían ${ }^{73}$. Es altamente probable que, como coinciden las fuentes principales, la legitimidad en el nacimiento fuera un argumento determinante habida cuenta de las duras consecuencias creadas por el conflicto continuado contra los mesenios $^{74}$; no es casualidad que, según recuerda Justino (3.4.8-9), fuera al alcanzar la edad de treinta años, justamente la que marca el paso a la edad adulta y el acceso a la ciudadanía plena, cuando los partenias, ante el temor de la indigencia, se encomiendan a Falanto ${ }^{75}$. La stasis generada en el seno de la comunidad solo podía resolverse con la salida forzada del grupo perdedor (Pl. Leg. 708b y 740e lo recomienda como medida no cruenta), que no solo restaura el orden natural y cívico, sino que también purifica la contaminación religiosa en la que se ha incurrido ${ }^{76}$. En el siglo III a. C. el poeta Calímaco cantaba que Tarento fue fundada por aquellos que, más que ninguno, descendían de Heracles (fr. 617 Pfeiffer). En este sentido, Delfos actuó, con sus oráculos, como un efectivo elemento legitimador de este proceso.

\section{Bibliografía}

Alessandrì, Salvatore. «I Phalantiadi di Taranto». En Studi in onore di Dinu Adamasteanu, 165-174. Galatina: Congedo, 1983.

Amandry, Pierre. «Notes de topographie et d'architecture delphiques II. Le monument commémoratif de la victoire des Tarentins sur les Peucétiens». Bulletin de correspondance hellénique 73 (1949): 447-463.

73. Cartledge, Sparte, 123-124; Morgan, Athletes, 169-171, y más extensamente Nafissi, Nascita, 35-81, que establece una conexión con la Gran Retra atribuida a Licurgo; Malkin, Myth, 142, hace una interesante analogía con los neodamodeis (hilotas liberados por su prestación militar) que Esparta asentó en Lépreo, en territorio disputado a los eleos; cf. Meier, Aristokraten, 126-131, solo que él sitúa el contexto en la segunda mitad del siglo VII.

74. Supra n. 30.

75. Domínguez Monedero, «Phocaeensium», 66-67.

76. Dougherty, «Murder», 182, 184. De la otra parte, de la de la colonia, según McGlew, Tyranny, 168-169, la "expiación» del fundador «articulated the colony's own distinct history of autonomy". 


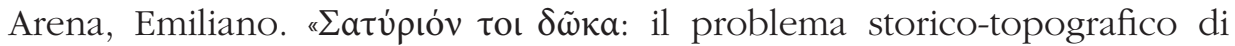
Satyrion nella tradizione degli oracoli delfici relativi alla fondazione di Tarantom. Studi di Antichità 10 (1997): 255-290.

Bérard, Jean. La colonisation grecque de l'Italie Méridionale et de la Sicile dans l'Antiquité. 2. ${ }^{\mathrm{a}}$ ed. Paris: PUF, 1957.

Beschi, Luigi. "I donari dei Tarantini a Delfi: alcune osservazioni». En Aparchai: Nuove ricerche e studi sulla Magna Grecia e la Sicilia antica in onore di Paolo Enrico Arias, Maria Letizia Gualandi, Luciano Massei y Salvattore Settis (a. c.), 227- 238. Pisa: Giardini, 1982.

Bogino, Liana. "In margine alla versione eforea sulla fondazione di Taranto». Miscellanea Greca e Romana 18 (1994): 1-13.

Boschung, Dietrich. «Die archaischen Nekropolen von Tarent». En Catalogo del Museo Nazionale Archeologico di Taranto III 1, Taranto. La necropoli. Aspetti e problemi della documentazione archeologica dal VII al I sec. a.C., Enzo Lippolis (a. c.), 176-182. Taranto: La Colomba, 1994.

Burgers, Gert-Jan. «Identità di comunità nel mondo indigeno del Salento e il caso studio di L'Amastuola». En Segni di appartenenza e identià di comunità nel mondo indigeno, Giovanna Greco y Bianca Ferrara (a. c.), 345-354. Napoli: Naus Editoria, 2014.

Burgers, Gert-Jan y Jan Paul Crielaard. "Greek colonists and indigenous populations at L'Amastuola, southern Italy». Bulletin Antieke Beschaving 82 (2007): 77-114.

Burgers, Gert-Jan y Jan Paul Crielaard. «Mobilità, migrazioni e fondazioni nel Tarantino arcaico: il caso di L'Amastuola». En Alle origini della Magna Grecia. Mobilità migrazioni fondazioni. Atti del L Convegno di Studi sulla Magna Grecia, 525-548. Taranto: Istituto per la Storia e l'Archeologia della Magna Grecia, 2012.

Burgers, Gert-Jan y Jan Paul Crielaard. «The Migrant's Identity: 'Greeks' and 'Natives' at L'Amastuola, Southern Italy». En Conceptualising early Colonisation, editado por Lieve Donnellan, Valentino Nizzo y GertJan Burgers, 225-237. Bruxelles-Rome: Belgisch Historisch Instituut te Rome, 2016.

Carlier, Pierre. La royauté en Grèce avant Alexandre. Strasbourg: AECR, 1984.

Carroccio, Benedetto. "Le iconografie monetali in Messapia e il 'mistero' Taras". En La monetazione pugliese dall'età classica al medioevo 3: Le monete della Messapia. La monetazione angioina nel Regno di Napoli (Atti del III Congresso Nazionale di Numismatica, Bari, 12-13 novembre 2010), Giuseppe Colluci (a. c.), 105-130. Bari: Circolo Numismatico Pugliese, 2011. 
Cartledge, Paul Anthony. Sparta and Lakonia. A Regional History 1300362 B.C. London: Routledge \& Kegan, 1979.

Corrado, Margherita. «Una nuova identità per il 'delfiniere' delle monete di Taranto: l'Apollo delfico oikistés". Atti e Memorie della Società Magna Grecia 1 (2016): 33-41.

Corsano, Marinella. «Sparte et Tarente: le mythe de fondation d'une colonie». Revue de l'Histoire des Religions 196 (1979): 113-140.

Crielaard, Jan Paul y Gert-Jan Burgers. "Communicating Identity in an Italic-Greek Community; the Case of L'Amastuola (Salento)». En Communicating Identity in Italic Iron Age Communities, editado por Margarita Gleba y Helle W. Horsnaes, 73-89. Oxford: Oxbow Books, 2011.

Crielaard, Jan Paul y Gert-Jan Burgers. "Greek colonists and indigenous populations at L'Amastuola, southern Italy II', Bulletin Antieke Beschaving 87 (2012): 59-96.

David, Ephraim. «Sparta's Social Hair». Eranos 90 (1992): 11-21.

De Juliis, Ettore. Taranto. Bari: Edipuglia, 2000.

Defradas, Jean. Les thèmes de la propagande delphique. 2. ${ }^{a}$ ed. Paris: Les Belles Lettres, 1972.

Domínguez Monedero, Adolfo J. «Phocaeensium iuventus ... Massiliam ... condidit (Iust., XLIII, 3, 4): Edad y dependencia en la definición de los contingentes colonizadores griegos». En Las edades de la dependencia durante la Antigüedad, editado por María del Mar Myro, Juan Miguel Casillas, Jaime Alvar y Domingo Plácido, 55-79. Madrid: Ediciones Clásicas, 2000.

Domínguez Monedero, Adolfo J. «Los oráculos, guía de la navegación y la colonización”. En La religión del mar: dioses y ritos de navegación en el Mediterráneo antiguo, coordinado por Eduardo Ferrer Albelda, M. ${ }^{a}$ Cruz Marín Ceballos y Álvaro Pereira Delgado, 67-90. Sevilla: Ediciones Universidad de Sevilla, 2012.

Dougherty, Carol. «When Rain Falls from the Clear Blue Sky: Riddles and Colonization Oracles", Classical Antiquity 11 (1992): 28-44.

Dougherty, Carol. The Poetics of Colonization: From City to Text in Archaic Greece. Oxford: Oxford University Press, 1993.

Dougherty, Carol. "It's Murder to Found a Colony». En Cultural Poetics in Archaic Greece: Cult, Performance, Politics, editado por Carol Dougherty y Leslie Kurke, 178-198. Oxford: Oxford University Press, 1998.

Dunbabin, Thomas James. The Western Greeks. The History of Sicily and South Italy from the Foundation of the Greek Colonies to 480 B.C. Oxford: Oxford Clarendon Press, 1948. 
Esposito, Arianna. «Identités tarentines et recompositions mémorielles: les offrandes de Delphes». En Another Way of Being Greek. Interactions and Cultural Innovations of the Greeks in a Colonial Milieu, editado por M. Costanzi y M. Dana, Colloquia Antiqua 20: 213-234. Leuven: Peeters, 2020.

Fontenrose, Joseph. The Delphic Oracle. Its Responses and Operations with a Catalogue of Responses. Berkeley: University of California Press, 1978.

Fornis, César. Esparta. La historia, el cosmos y la leyenda de los antiguos espartanos. Sevilla: Editorial Universidad de Sevilla, 2016.

Fornis, César. "Celebrando a Apolo y a Jacinto en Esparta: el Amyklaîon y las fiestas Jacintias». En Guerra y paz. Las religiones ante los conflictos bélicos en la Antigüedad (Spal Monografías XXIII), editado por Alfonso Álvarez-Ossorio Rivas, Eduardo Ferrer Albelda y Álvaro Delgado Pereira, 109-125. Sevilla: Editorial Universidad de Sevilla, 2016.

Fornis, César. El mito de Esparta. Un itinerario por la cultura occidental. Madrid: Alianza, 2019.

Forrest, William George. "Colonization and the Rise of Delphi». Historia 6 (1957): 160-175.

Gasperini, Lidio. "Cultos de héroes fundadores: Batos en Oriente, Taras en Occidente». Gerión 16 (1998): 143-159.

Giannelli, Giulio. Culti e miti della Magna Grecia. Contributo alla storia più antica delle colonie greche in Occidente. Firenze: R. Bemporad \& Figlio Editori, 1924.

Goegebeur, Werner. «Myskellos, Aithra et Phalanthos: concordance entre les traditions de fondation de Tarente et de Crotone?». En Studia varia Bruxellensia II, editado por Rudolf De Smet, Henri Melaerts y Cecilia Saerens, 83-99. Leuven: Peeters, 1990.

Goegebeur, Werner. "Aithra et Phalantos: poux et pleurs, pluie et ciel bleu». En Studia Varia Bruxellensia III, editado por Henri Melaerts, Rudolf De Smet y Cecilia Saerens, 63-81. Leuven: Peeters, 1994.

Kennell, Nigel. Spartans. A New History. Oxford: Wylie-Blackwell, 2010.

Kindt, Julia. Revisiting Delphi. Religion and Storytelling in Ancient Greece. Cambridge: Cambridge University Press, 2016.

Lacroix, Léon. "Sur quelques offrandes à l'Apollon de Delphes». Revue Belgue de Numismatique 100 (1954): 11-23.

Lacroix, Léon. Monnaies et colonisation dans l'Occident grec. Bruxelles: Palais des Académies, 1965.

Lacroix, Léon. «À propos des offrandes à l'Apollon de Delphes et du témoignage de Pausanias: du réel à l'imaginaire». Bulletin de Correspondance Hellénique 116 (1992): 157-176. 
Lippolis, Enzo. "Le testimonianze del culto in Taranto greca». Taras 2 (1982): 81-135.

Lippolis, Enzo, Salvatore Garraffo y Massimo Nafissi. Culti greci in Occidente, I: Taranto. Taranto: Istituto per la Storia e l'Archeologia della Magna Grecia, 1995.

Lo Porto, Felice Gino. «Satyrion (Taranto). Scavi e ricerche nel luogo del più antico insediamento laconico in Puglia». Notizie Scavi d'Antichità 18 (1964): 177-279.

Lo Porto, Felice Gino. "Topografia antica di Taranto". En Taranto nella civiltà della Magna Grecia, Atti X Convegno di Studi sulla Magna Grecia (Taranto, ottobre 1970), 343-383. Napoli: Istituto per la Storia e l'Archeologia della Magna Grecia, 1971.

Lombardo, Mario. «Tombe, necropoli e riti funerari in Messapia: evidenze e problemi». Studi di Antichità 10 (1994): 26-45.

Lombardo, Mario. "ПНМА ІАПҮГЕ $\Sigma \Sigma$ I: rapporti con gli Iapigi e aspetti dell'identità di Taranto». En Taranto e il Mediterraneo. Atti XLI Convegno di Studi sulla Magna Grecia (12-16 ottobre 2001), 253-289. Taranto: Istituto per la Storia e l'Archeologia della Magna Grecia, 2002. Londey, Peter. "Greek Colonists and Delphi». En Greek Colonists and Native Populations. Proceedings of the First Australian Congress of Classical Archaeology, editado por Jean-Pierre Descoeudres, 117-127. Oxford: Oxford Clarendon Press, 1990.

Maddoli, Gianfranco. «Falanto spartiata (Strabone VI 3, 2 = Antioco F 13 J)». Mélanges de l'École Française de Rome 95 (1983): 555-564.

Malkin, Irad. Religion and Colonization in Ancient Greece. Leiden: Brill, 1987.

Malkin, Irad. Myth and Territory in the Spartan Mediterranean. Cambridge: Cambridge University Press, 1994.

Maurizio, Lisa. Delphic Narratives. Recontextualizing the Pythia and her Prophecies. Diss. Princeton University, 1993.

Maurizio, Lisa. «Delphic Oracles as Oral Performances: Authenticity and Historical Evidence». Classical Antiquity 16 (1997): 308-334.

McGlew, James F. Tyranny and Political Culture in Ancient Greece. Ithaca: Cornell University Press, 1993.

Meier, Mischa. Aristokraten und Damoden. Untersuchungen zur inneren Entwicklung Spartas im 7. Jahrbunder v. Chr. und zur politischen Funktion der Dichtung des Tyrtaios. Stuttgart: Franz Steiner Verlag, 1998.

Morgan, Catherine. Athletes and Oracles: The transformation of Olympia and Delphi in the eighth century B.C. Cambridge: Cambridge University Press, 1990. 
Moscati Castelnuovo, Luisa. "Iloti e fondazione di Taranto». Latomus 50 (1991): 64-79.

Moscati Castelnuovo, Luisa. "Ecisti e oracoli». Rivista Storica dell'Antichità 39 (2009): 9-30.

Musti, Domenico. "Sul ruolo storico della servitù ilotica. Servitù e fondazioni coloniali». Studi Storici 26 (1985): 857-872.

Nafissi, Massimo. La nascità del Kosmos. Studi sulla storia e società di Sparta. Napoli: Edizioni Scientifiche Italiane, 1991.

Nafissi, Massimo. "Rapporti fra le poleis e dinamiche interne nelle tradizioni mitico- storiche: Siri-Eraclea e Taranto". En Mito e storia in Magna Grecia, Atti XXXVII Convegno di Studi sulla Magna Grecia (Taranto, 4-7 ottobre 1996), 305-322. Taranto: Istituto per la Storia e l'Archeologia della Magna Grecia, 1997.

Nafissi, Massimo. "From Sparta to Taras: nomina, ktiseis and relationships between colony and mother city». En Sparta: New Perspectives, editado por Stephen Hodkinson y Anton Powell, 245-272. London: Duckworth, 1999.

Nafissi, Massimo. "Lykourgos the Spartan 'Lawgiver': Ancient Beliefs and Modern Scholarship». En A Companion to Sparta, editado por Anton Powell, 93-123. Hoboken: Wylie, 2018.

Neeft, Cornelius W. "Tarantine Graves Containing Corinthian Pottery». En Catalogo del Museo Nazionale Archeologico di Taranto III 1, Taranto. La necropoli. Aspetti e problemi della documentazione archeologica dal VII al I sec. a.C., Enzo Lippolis (a. c.), 184-237. Taranto: La Colomba, 1994.

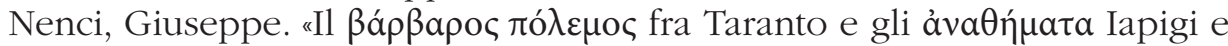
gli tarentini a Delfi». Annali Scuola Normale Superiore di Pisa 6 (1976): 719-738.

Paradiso, Annalisa. "Gli epeunatti spartani». Index. Quaderni Camerti di Studi Romanistici 12 (1983-84): 355-365.

Parke, Herbert William y Donald Ernest Wilson Wormell. The Delphic Oracle. Vol. I: The History. Oxford: Blackwell, 1956.

Parke, Herbert William y Donald Ernest Wilson Wormell. The Delphic Oracle. Vol. II: The Oracular Responses. Oxford: Blackwell, 1956.

Parker, Victor. «The Dates of the Messenian Wars». Chiron 21 (1991): 25-43. Pembroke, Simon. "Femmes et enfants dans les fondations de Locres et de Tarente». Annales. Economies, Sociétés, Civilisations 5 (1970): 12401270.

Philippides, Marios. "The Partheniai and the Foundation of Taras". The Ancient World 2.3 (1979): 79-82.

Presicci, Felice. Falanto e i Parteni. Storia, Miti, Leggende sulla colonizzazione spartana di Taranto. Taranto: Piero Lacaita Editore, 1990. 
Pugliese Carratelli, Giovanni. "Per la storia dei culti di Taranto». En Taranto nella civiltà della Magna Grecia, Atti X Convegno di Studi sulla Magna Grecia (Taranto, ottobre 1970), 133-146. Napoli: Istituto per la Storia e l'Archeologia della Magna Grecia, 1971.

Qviller, Bjorn. "Reconstructing the Spartan Partheniai: many guesses and a few facts». Symbolae Osloenses 71 (1996): 34-41.

Richer, Nicholas. La religion des Spartiates. Croyances et cultes dans l'Antiquité. Paris: Les Belles Lettres, 2012.

Russo, Federico. "I donari tarantini a Delfi". Annali Scuola Normale Superiore di Pisa 9 (2004): 79-102.

Sakellariou, Michel. Between Memory and Oblivion. The Transmission of Early Greek Historical Traditions. Athens: National Hellenic Research Foundation, 1990.

Stibbe, Conrad M. "Sparta und Tarent". Mededelingen van het Nederlands Instituut te Rome 37 (1975): 27-46.

Studniczka, Franz. Kyrene, eine altgriechische Göttin. Leipzig: Brockhaus, 1890.

Suárez de la Torre, Emilio. "Gli oracoli relativi alla colonizzazione della Sicilia e della Magna Grecia». Quaderni Urbinati di Cultura Classica 77 (1994): 7-37.

Valdés Guía, Miriam. «El culto a Zeus Eleutherios en época arcaica: liberación de esclavos/dependientes y constitución de ciudadanías». En Histoire, espaces et marges de l'Antiquité, II, 291-323. Besançon: Institut des Sciences et Techniques de l'Antiquité, 2003.

Valdés Guía, Miriam. "El culto de Afrodita armada en Amiclas (Esparta) y la fundación de Tarento». ARYS. Antigüedad, Religiones y Sociedades 7 (2006-08): 68-92.

Wide, Samuel. Lakonische Kulte. Leipzig: Teubner, 1893.

Wuilleumier, Pierre. Tarente, des origines à la conquête romaine. Paris: De Boccard, 1939. 